\title{
Chloroquine diphosphate suppresses liver cancer via inducing apoptosis in Wistar rats using interventional therapy
}

\author{
XIAOGUANG HAO ${ }^{1}$ and WEIJING LI $^{2}$ \\ Departments of ${ }^{1}$ Radiology and ${ }^{2}$ Anesthesiology, The Fourth Hospital of Hebei Medicine University, \\ Shijiazhuang, Hebei 050000, P.R. China
}

Received July 20, 2020; Accepted December 8, 2020

DOI: $10.3892 / 01.2021 .12494$

\begin{abstract}
Liver cancer ranks as the second leading cause of cancer-associated mortality worldwide. To date, neither current ablation therapy nor chemotherapy are considered ideal in improving the outcome of liver cancer. Therefore, more effective therapies for treating this devastating disease are urgently required. Interventional therapy has been used for numerous years in the treatment of different types of cancer, and is characterized by the direct delivery of anticancer drugs into the tumor. It has been reported that antimalarial chloroquine diphosphate (CQ) exerts effective anticancer activity against several types of cancer. However, its effect on liver cancer remains unclear. Therefore, in the present study, 2D monolayer cell culture and 3D spheroid in vitro models, and a rat model, were utilized to investigate the effect of CQ on liver cancer. CQ demonstrated an effective anticancer effect on HepG2 cells and 3D liver spheroids. Furthermore, the drug significantly inhibited cell growth and viability in the $2 \mathrm{D}$ and $3 \mathrm{D}$ in vitro models. The CQ-based intervention treatment effectively attenuated tumor size and weight, increased food intake and consumption of drinking water, and improved body weight and survival rate of rats in the in vivo model. In addition, treatment with CQ potently increased the expression levels of the apoptosis-related genes. Taken together, the findings of the present study may provide a novel insight into the development of safe and effective treatments for liver cancer.
\end{abstract}

\section{Introduction}

As one of the most severe human malignant diseases, liver cancer ranks as the second leading cause of cancer-associated mortality worldwide (1). The annual liver cancer-associated mortalities are estimated at $\sim 700,000$ worldwide (2). Liver cancer is often extremely heterogeneous, making the treatment

Correspondence to: Dr Weijing Li, Department of Anesthesiology, The Fourth Hospital of Hebei Medicine University, Shijiazhuang, Hebei 050000, P.R. China

E-mail: hxg820602@126.com

Key words: chloroquine diphosphate, liver cancer, apoptosis, interventional therapy of the disease even more difficult (2). Compared with developed countries, the incidence of liver cancer exhibits an increasing trend in developing countries (3). The morbidity rate of liver cancer ranks second among all cancer-associated mortalities (4). Liver cancer is further classified into primary and secondary liver cancer. Primary liver cancers mainly include hepatocellular carcinoma (HCC), intrahepatic cholangiocarcinoma (ICC), and combined HCC and ICC, while secondary liver cancer mainly refers to metastatic disease (5). Several factors have been associated with liver cancer, including viral infections such as hepatitis B virus and hepatitis C viruses, fatty liver disease, smoking, obesity, diabetes mellitus, iron overload, alcohol abuse and deregulation of metabolism (6). The early stage of liver cancer may often be asymptomatic; therefore, the majority of patients are diagnosed in advanced stages of the disease, when metastasis has already occurred, thus leading to a poor prognosis and a high mortality rate (7).

As a heterogeneous malignant disease, liver cancer is considered one of the most difficult types of cancer to treat (2). To date, multidisciplinary approaches are used to treat liver cancer based on the clinical characteristics of each patient, including the complex interplay of tumor stage and the extent of underlying liver disease, as well as the patient's general health (8). A variety of therapies for liver cancer have been developed, mainly including cytotoxic chemotherapy, immunotherapy (immune-checkpoint), oncolytic virus therapy and novel targeted therapy (8). Other treatment strategies, including transarterial embolization (TAE), where embolic particles without chemotherapy are used, or transarterial chemoembolization (TACE), where embolic particles are combined with chemotherapeutic drugs, have been reported to be effective against liver cancer via regulating arterial blood supply to induce tumor necrosis (1). However, neither current ablation therapies nor chemotherapy are ideal in improving the outcomes of patients with liver cancer; therefore, more effective therapies for treating this devastating disease are urgently required (9).

The intravenous administration of tumoricidal agents is limited due to their inability to access the entire tumor mass, which is mediated by the high interstitial pressure of the solid tumor (10). Recently, the minimally invasive interventional drug delivery method for treating human cancer has received increasing attention (11). In interventional therapy, a needle or catheter that enters the body through a fine skin incision 
is guided by an imaging system (fluoroscopy) to the solid tumor (11). Compared with conventional therapies, in interventional therapy, the anticancer drugs are directly delivered into the tumor, thereby providing several advantages, including fewer anesthetic administrations, fewer traumas, less pain and shorter hospitalization time (10).

Chloroquine is a chemically synthesized compound, which has been widely used as an antimalarial agent for a few decades (12). Recently, chloroquine and its derivatives have been reported to exert antiviral effects against SARS-CoV-2 infection (13). In addition, chloroquine diphosphate (CQ) was used to treat Plasmodium falciparum parasite infections (14). Accumulating evidence has indicated that chloroquine and its derivatives exert anticancer effects. For example, Wei et al (15) demonstrated that CQ may suppress pancreatic cancer via modulating the autophagy process. Furthermore, a study revealed that CQ exerted antitumor effect on breast cancer in a murine model (16). Sasaki et al (17) demonstrated that 5-fluorouracil combined with chloroquine may suppress colon cancer in a colon cancer cell line and mouse model. However, the effects of chloroquine and its derivatives on liver cancer remain to be investigated. Therefore, in the present study, an interventional therapy was applied to investigate the effects of CQ on liver cancer in C57BL/6 mice. The findings of the present study may provide novel insight into the development of novel treatment strategies against liver cancer.

\section{Materials and methods}

Chemicalsandreagents.CQ was purchasedfromSigma-Aldrich; Merck KGaA (cat. no. 50-63-5). CellTiter-Glo ${ }^{\circledR}$ Luminescent Cell Viability assay (cat. no. G7570) and CellTiter-Glo ${ }^{\circledR}$ 3D Cell Viability assay (cat. no. G9681) were both obtained from Promega Corporation. The Cell Counting Kit-8 (CCK-8) assay was purchased from Beyotime Institute of Biotechnology (cat. no. C0037) and Dulbecco's phosphate-buffered saline (DPBS; cat. no. 14190250) from Thermo Fisher Scientific, Inc. All other reagents used were of analytical grade.

Cell culture. Human liver cancer HepG2 cells were purchased from the American Type Culture Collection (HB-8065 ${ }^{\mathrm{TM}}$ ). The cells were maintained in Dulbecco's modified Eagle's medium (DMEM; cat. no. 11995065), supplemented with $10 \%$ fetal bovine serum (FBS; cat. no. 16140071) and $50 \mathrm{U} / \mathrm{ml}$ penicillin-streptomycin (cat. no. 15070063; all Gibco; Thermo Fisher Scientific, Inc.) at $37^{\circ} \mathrm{C}$ in a humidified atmosphere of $5 \% \mathrm{CO}_{2}$. Upon reaching 80-90\% confluence, the cells were passaged.

$3 D$ liver spheroid culture. A 3D liver spheroid culture was performed and modified as previously described $(18,19)$. In brief, HepG2 cells were cultured in $75 \mathrm{~cm}^{2}$ cell culture flasks, trypsinized using the TrypLE ${ }^{\mathrm{TM}}$ Express Enzyme kit (cat. no. 12605010; Thermo Fisher Scientific, Inc.) and pelleted by centrifugation at $100 \mathrm{x} \mathrm{g}$ for $5 \mathrm{~min}$ at $4^{\circ} \mathrm{C}$. Cells were resuspended, and were then seeded onto a Corning Matrigel Growth Factor Reduced Basement Membrane Matrix (cat. no. 356231; Corning Incorporated). The morphology of 3D liver spheroids was observed under a phase-contrast microscope (Olympus Corporation).

In vitro drug treatment assay. Subsequently, the effect of CQ on HepG2 cell growth and 3D spheroids was investigated. At least two independent experiments or four replicates were performed. For the HepG2 monolayer cultures, the cells $\left(1 \times 10^{5}\right.$ cells/well $)$ were seeded onto 48 well-plates and, upon reaching 50-60\% confluence, they were treated with the indicated concentrations of CQ $(0,1,5,10,50$ and $100 \mu \mathrm{M})$. For 3D liver spheroids, when 3D liver spheroids were formed, they were harvested from Matrigel using cold PBS, followed by filtration through a $70-\mu \mathrm{m}$ cell strainer. Next, the spheroids were centrifuged at $100 \mathrm{x} g$ for 5 min at $4^{\circ} \mathrm{C}$, added into the 48 -well plates, and treated with the indicated concentrations of CQ $(0,1,5,10,50$ and $50 \mu \mathrm{M})$.

CCK-8 assays. HepG2 cell viability was assessed using a CCK-8 assay (cat. no. C0037; Beyotime Institute of Biotechnology), according to the manufacturers' protocols. In brief, cells $\left(2 \times 10^{3}\right.$ cells/well) or 3D liver spheroids were seeded onto a 96-well plate, supplemented with $100 \mu$ l culture medium containing the indicated concentrations of $\mathrm{CQ}$ and cultured for $48 \mathrm{~h}$ at $37^{\circ} \mathrm{C}$ in a humidified atmosphere containing $5 \% \mathrm{CO}_{2}$. Subsequently, $10 \mu \mathrm{l}$ CCK-8 reagent was added into the culture medium and cells were incubated for an additional $2 \mathrm{~h}$. The absorbance at $450 \mathrm{~nm}$ was measured using a microplate reader (Thermo Fisher Scientific, Inc.).

$R N A$ extraction and reverse transcription-quantitative polymerase chain reaction ( $R T-q P C R)$. Total RNA was extracted from cells and tissues using the Beyozol total RNA extraction kit (cat. no. R0011; Thermo Fisher Scientific, Inc.), according to the manufacturers' protocol. The RNA was reverse transcribed into complementary DNA (cDNA) using the PrimeScript ${ }^{\mathrm{TM}}$ RT Master mix (cat. no. RR036A; Takara Bio, Inc.), according to the manufacturers' protocol.Subsequently, RT-qPCR was performed using the TB Green ${ }^{\circledR}$ Fast qPCR mix (cat. no. RR036A; Takara Bio, Inc.) on the ABI Prism 7500 system (Applied Biosystems; Thermo Fisher Scientific, Inc.). The pre-denaturation and denaturation temperatures were set at $95^{\circ} \mathrm{C}$ and that of annealing/extension at $60^{\circ} \mathrm{C}$. Pre-denaturation was performed for $10 \mathrm{~min}$, denaturation for $15 \mathrm{sec}$ and annealing/extension for $60 \mathrm{sec}$. The number of cycles was set to 40 . The relative expression of the target genes was analyzed using the $2^{-\Delta \Delta \mathrm{Cq}}$ method (20). GAPDH was used as a housekeeping reference gene. All primer sequences are listed in Table I.

CellTiter-Glo Luminescent Cell Viability assay. To measure the viability of cells and 3D liver spheroids, 2D and 3D CellTiter-Glo Luminescent Cell Viability assays were performed. In brief, for HepG2 cells, cells were seeded onto a 96-well culture plate at a density of $3 \times 10^{3}$ cells $/ 100 \mu \mathrm{l}$ and treated with different concentrations of CQ for $48 \mathrm{~h}$ at $37^{\circ} \mathrm{C}$ in a humidified atmosphere containing $5 \% \mathrm{CO}_{2}$. For 3D liver spheroids, spheroids were isolated from the Matrigel, seeded onto a 100x pre-coated Matrigel 96-well culture plate at a density of $\sim 100$ spheroids $/ 100 \mu 1$, and treated with different concentrations of $\mathrm{CQ}$ for $48 \mathrm{~h}$ at $37^{\circ} \mathrm{C}$ in a humidified atmosphere containing $5 \% \mathrm{CO}_{2}$. Luminescence signals were measured using the LMax II kit (Molecular Devices, LLC). The concentration of ATP was calculated based on an ATP reference calibration curve (cat. no. 18330019; Thermo Fisher Scientific, Inc.).

Animals, grouping and animal experiments. All animal experiments were performed according to the Guide for the Care and Use of Laboratory Animals from the National 
Table I. Primers used for reverse transcription-quantitative polymerase chain reaction.

\begin{tabular}{lllr}
\hline Primer & & Primer sequences & Tm \\
\hline Caspase-3 & Sense & TGCTATTGTGAGGCGGTTGT & 59.96 \\
& Antisense & TCACGGCCTGGGATTTCAAG & 60.32 \\
Caspase-9 & Sense & AGGCCCATATGATCGAGGA & 59.88 \\
& Antisense & TCGACAACTTTGCTGCTTGC & 59.97 \\
GAPDH & Sense & ATGTTGCAACCGGGAAGGAA & 60.18 \\
& Antisense & GCATCACCCGGAGGAGAAAT & 59.82 \\
\hline
\end{tabular}

Institutes of Health, and the study was approved by the Animal Experimentation Committee of The Fourth Hospital of Medical University (Shijiazhuang, China). A total of 30 male Wistar rats (age, 6-7 weeks old; weight, 200 $\pm 20 \mathrm{~g}$ ) and 3 male young Wistar rats (age, 3-4 weeks; weight, $100 \pm 10 \mathrm{~g}$ ) were obtained from the Experimental Center of The Fourth Hospital of Medical University. All rats were housed in plastic cages (dimensions, 500×360×200 mm). Each cage held 3 rats of the same sex and all cages were placed in the same specific-pathogen-free animal room. The environment conditions of the animal room were strictly controlled and maintained at a temperature of $20.4-23.0^{\circ} \mathrm{C}$, a relative humidity of 40.1-68.9\%, an air change 8-15 times/h, a 12/12 h-light/dark cycle, and ad libitum access to food. The rats were sacrificed using deep anesthesia with thiopental $(50 \mathrm{mg} / \mathrm{kg})$. Death was confirmed using cervical dislocation. HepG2 cell suspensions were prepared (density, $1 \times 10^{4}$ cells $/ \mathrm{ml}$ ), and three young rats were subcutaneously injected with $0.3 \mathrm{ml}$ of the prepared cell suspension. Following 10 days from the injection, the tumors were isolated and dissected into $1.5 \mathrm{~mm}^{3}$ pieces. Subsequently, the dissected tissues were implanted under the capsule of the left liver lobe of the other $30 \mathrm{Wistar}$ rats. The rats were intramuscularly injected with 30,000 units long-acting penicillin. The rats were maintained in a disease-free environment, had ad libitum access to food and water and the litter was changed every other day. On the 11th day following implantation, the rats were divided into three groups, namely the control group (no treatment) and the $0.5-$ and $1.5-\mathrm{mg} / \mathrm{kg}$ CQ treatment groups. Following anesthetization, the hepatic artery of the animals was retrograde intubated into the gastroduodenal artery (Portex PE10 microcatheter; inner diameter, $0.28 \mathrm{~mm}$; outer diameter, $0.61 \mathrm{~mm}$ ) and the experimental groups were then perfused with 0.5 and $1.5 \mathrm{mg} / \mathrm{kg} \mathrm{CQ}$ through the hepatic artery. Animals in the control group were perfused with $1 \mathrm{ml}$ saline. All animals were treated daily with CQ or saline for 9 days according to a previous study (21). At the end of the treatment period, animals were sacrificed, and the tumors were isolated, and their size was measured. The tumor volume was calculated as previously described (22). In brief, the tumor length and width were measured using a precise clipper, and the tumor volume was estimated using the following formula: $\mathrm{V}=\left(\mathrm{W}^{2} \times \mathrm{L}\right) / 2$, where $\mathrm{V}, \mathrm{W}$ and $\mathrm{L}$ indicate tumor volume, width, and length, respectively.

Flow cytometry. Cell suspensions were generated from tumor tissues, followed by rinsing with a total volume of $10 \mathrm{ml}$ of PBS buffer and washing twice in $10 \mathrm{ml}$ PBS buffer. Following the last wash step, the supernatant was discarded and the pellet of cells was suspended in washing buffer (PBS 5\% his $0.1 \% \mathrm{NaN} 3$ ). Cells were centrifuged for $5 \mathrm{~min}$ at $200 \mathrm{x} \mathrm{g}$ and $4^{\circ} \mathrm{C}$. The pellet was resuspended with $50 \mu \mathrm{l}$ primary anti-cytokeratin 19 antibody (cat. no. ab52625; Abcam) and anti-Sox9 (cat. no. ab185966; Abcam) diluted 5 times in washing buffer and incubated overnight at $4^{\circ} \mathrm{C}$. Cells were also incubated with the control isotype corresponding to each primary antibody. Following incubation, primary antibodies were removed and cells were washed for three times with washing buffer. Next, cells were incubated with goat anti-rabbit IgG H\&L (Alexa Fluor $^{\circledR}$ 488; cat. no. ab150077; Abcam) for $1 \mathrm{~h}$ at room temperature. Next, cells were analyzed by flow cytometry using a FACScalibur (BD Biosciences) with 488 channel. The data was analyzed using FlowJo software (v10; BD Biosciences).

Statistical analysis. All data are expressed as the mean \pm standard error of the mean. Pairwise comparisons of the analytical data were performed using an unpaired Student's t-test. For multiple comparisons, one-way analysis of variance was performed, followed by Bonferroni's and Dunnett's test. $\mathrm{P}<0.05$ was considered to indicate a statistically significant difference.

\section{Results}

$C Q$ potently inhibits the growth of HepG2 cells. To investigate the effect of CQ on cell growth, HepG2 cells were treated with different concentrations $(0,1,5,10,50$ and $100 \mu \mathrm{M})$ of CQ. The results demonstrated that CQ markedly attenuated the growth of HepG2 cells (Fig. 1A and B). To further investigate the effect of CQ on HepG2 cell viability, a CellTiter-Glo Luminescent Cell Viability assay was performed. Treatment of cells with 1, 5, 10, 50 and $100 \mu \mathrm{M}$ CQ significantly decreased the ATP concentration in HepG2 cells (Fig. 1C). Furthermore, the CCK-8 assay revealed that treatment with 1, 5, 10, 50 or $100 \mu \mathrm{M}$ CQ significantly inhibited HepG2 viability (Fig. 1D). Taken together, these results indicated that CQ may potently inhibit the growth of HepG2 cells in vitro.

$C Q$ potently inhibits the growth of $3 D$ liver spheroids. It has been reported that the $3 \mathrm{D}$ structure more precisely mimics the in vivo physiology, compared with 2D monolayer cells (23). Therefore, 3D liver spheroids were cultured to investigate the effects of CQ on the 3D model. CQ strongly suppressed the growth of 3D liver spheroids (Fig. 2A and B). To further investigate the effects of $\mathrm{CQ}$ on the viability of 3D liver spheroids, a CCK-8 assay was performed, demonstrating that treatment 

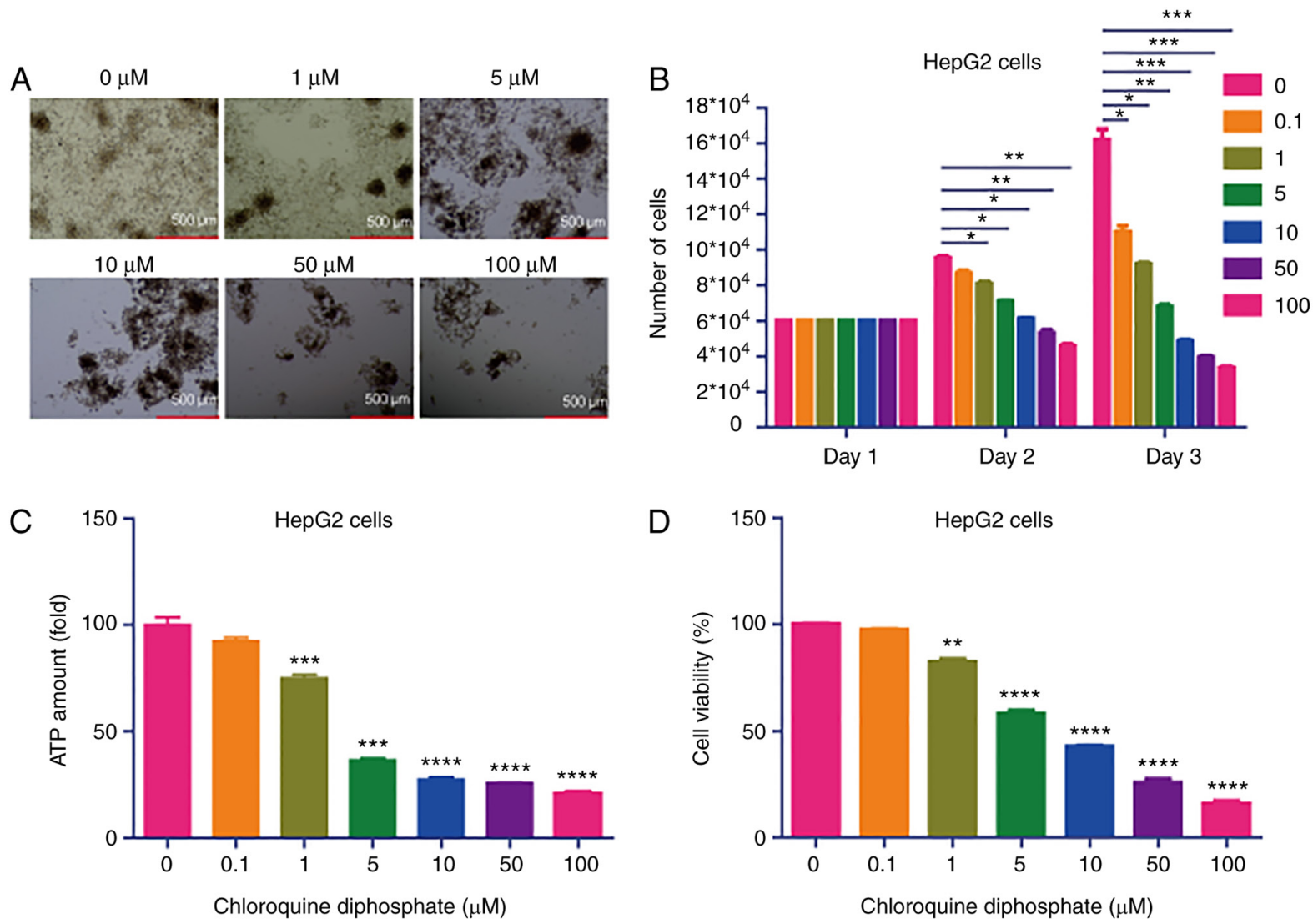

Figure 1. CQ potently inhibits HepG2 cell growth. (A) Morphology of HepG2 cells treated with different concentrations $(0,1,5,10,50$ and $100 \mu \mathrm{M})$ of CQ under a light microscope. (B) Quantification of the number of HepG2 cells treated with different concentrations $(0,1,5,10,50$ and $100 \mu \mathrm{M})$ of CQ ( $=6$ ). ${ }^{*} \mathrm{P}<0.05,{ }^{* *} \mathrm{P}<0.01$ and ${ }^{* * *} \mathrm{P}<0.001$ vs. the control group. (C) ATP concentration was measured in HepG2 cells treated with 1, 5, 10, 50 and $100 \mu \mathrm{M}$ CQ using a CellTiter-Glo Luminescent Cell Viability assay $(\mathrm{n}=10) .{ }^{* * *} \mathrm{P}<0.001$ and ${ }^{* * * * *} \mathrm{P}<0.0001$ vs. the control group. (D) Viability of HepG2 cells treated with $1,5,10,50$ and $100 \mu \mathrm{M}$ of CQ was determined using a Cell Counting kit-8 assay $(\mathrm{n}=10){ }^{* * *} \mathrm{P}<0.01$ and ${ }^{* * * *} \mathrm{P}<0.0001$ vs. the control group. CQ, chloroquine diphosphate.
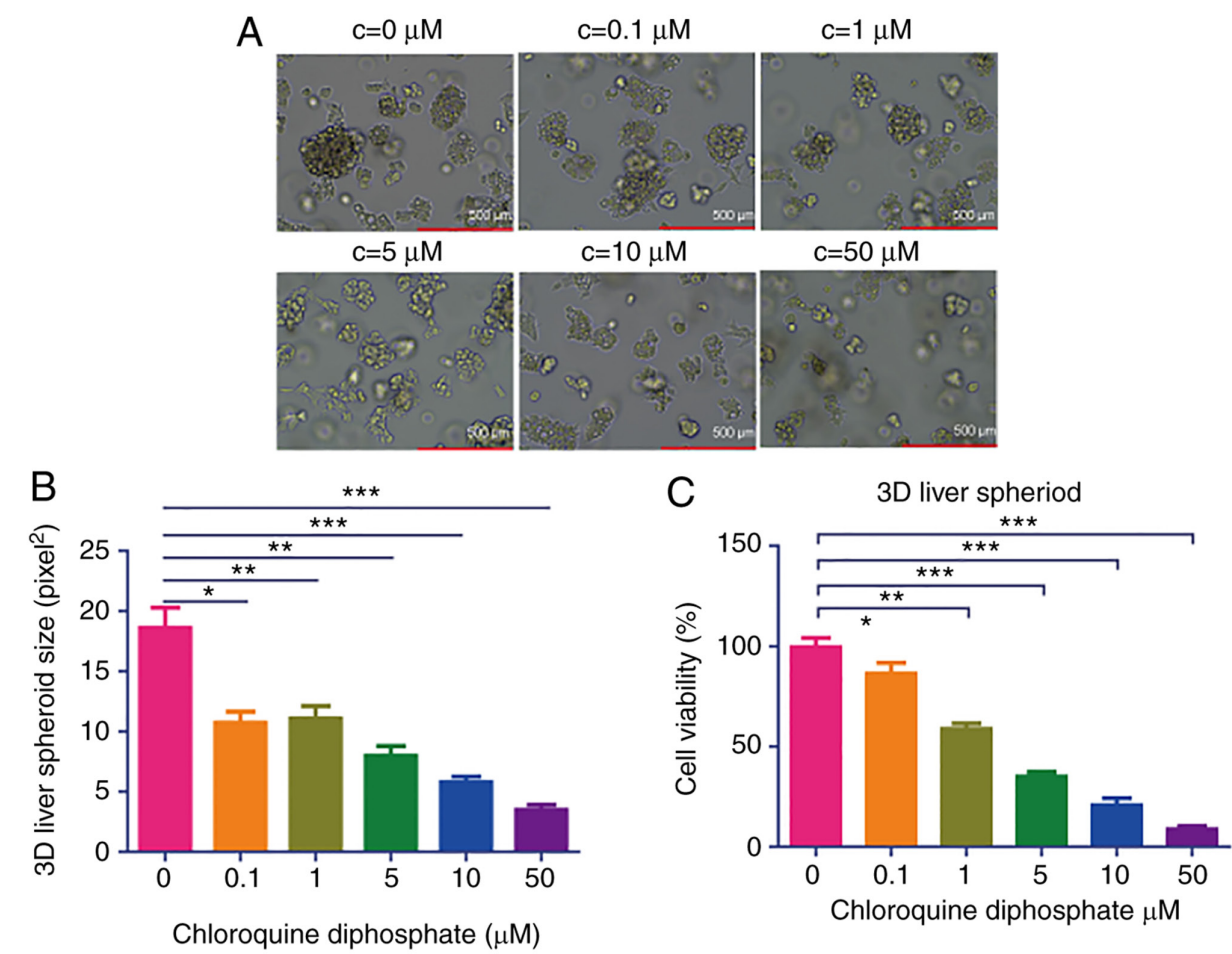

Figure 2. CQ potently inhibits the growth of 3D HepG2 spheroids. (A) Morphology of 3D liver spheroids treated with different concentrations $(0,1,5,10$ and $50 \mu \mathrm{M}$ ) of CQ under a light microscope. (B) The concentration of ATP in 3D liver spheroids treated with 1,5, 10 and $50 \mu \mathrm{M}$ CQ was measured using a CellTiter-Glo Luminescent Cell Viability assay $(\mathrm{n}=10) .{ }^{*} \mathrm{P}<0.05,{ }^{* * *} \mathrm{P}<0.01$ and ${ }^{* * * *} \mathrm{P}<0.001$ vs. the control group. (C) The viability of 3D liver spheroids treated with $1,5,10$ and $50 \mu \mathrm{M}$ of $\mathrm{CQ}$ was evaluated using a Cell Counting kit-8 assay ( $\mathrm{n}=10)$. ${ }^{*} \mathrm{P}<0.05,{ }^{* * *} \mathrm{P}<0.01$ and ${ }^{* * * *} \mathrm{P}<0.001$ vs. the control group.. CQ, chloroquine diphosphate. 
A

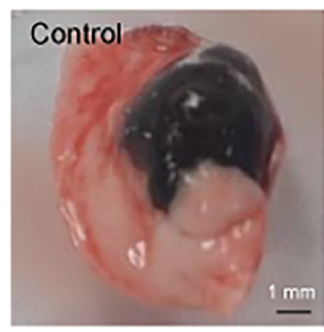

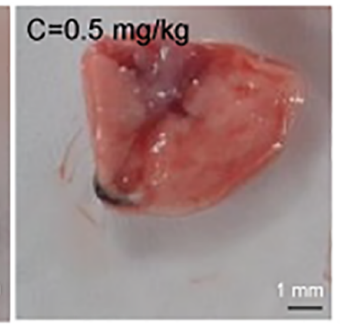

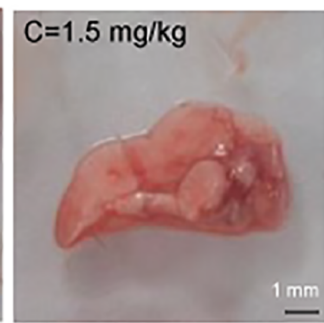

B

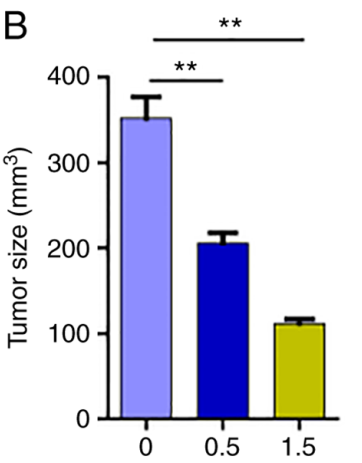

Chloroquine diphosphate (mg/kg)

F

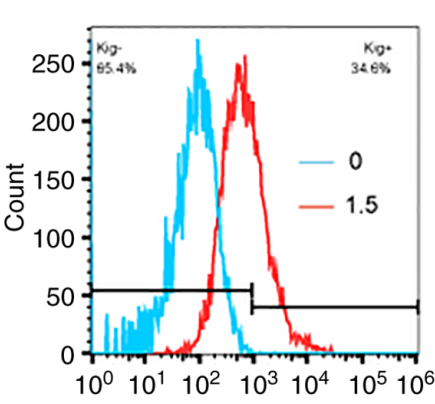

C

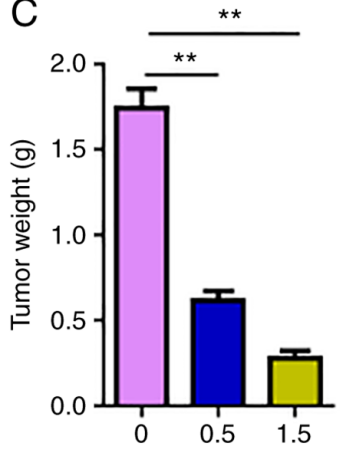

Chloroquine diphosphate $(\mathrm{mg} / \mathrm{kg})$
D

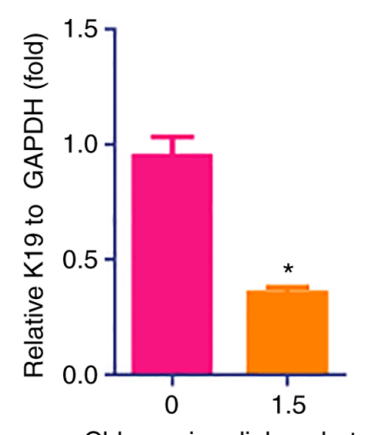

Chloroquine diphosphate $(\mathrm{mg} / \mathrm{kg})$

\section{E}

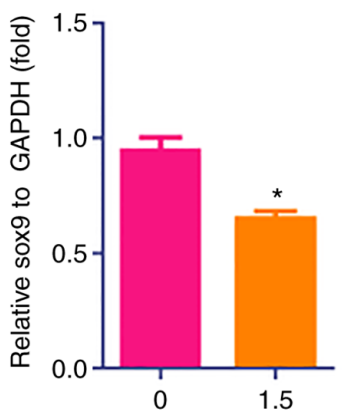

Chloroquine diphosphate $(\mathrm{mg} / \mathrm{kg})$

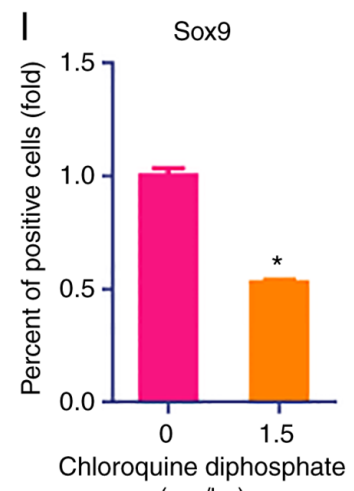

$(\mathrm{mg} / \mathrm{kg}$ )

Figure 3. CQ-based interventional therapy suppresses tumor growth in vivo. (A) Tumor images from rats treated with different doses of CQ. (B) Measurement of tumor size in rats treated with different concentrations of CQ $(n=10)$. ${ }^{* *} \mathrm{P}<0.01$ vs. the control group. (C) Measurement of tumor weight in rats treated with different doses of CQ $(\mathrm{n}=10) .{ }^{* *} \mathrm{P}<0.01$ vs. the control group. Treatment of cells with (D) 0.5 and (E) $1.5 \mathrm{mg} / \mathrm{kg}$ CQ downregulated the expression of K19 as detected by reverse transcription-quantitative polymerase chain reaction $(n=3)$. ${ }^{*} \mathrm{P}<0.05$. Flow cytometric analysis showing the decreased expression levels of (F and G) K19 (n=3) and (H and I) SOX9 (n=3) in cells treated with $1.5 \mathrm{mg} / \mathrm{kg} \mathrm{CQ}$. ${ }^{*} \mathrm{P}<0.05$ vs. the control group. CQ, chloroquine diphosphate.

with $1,5,10,50$ or $100 \mu \mathrm{M}$ CQ significantly inhibited 3D liver spheroid viability (Fig. 2C). These results confirmed that CQ may significantly inhibit the growth of 3D liver spheroids.

CQ-based interventional therapy attenuates tumor growth in vivo. Interventional therapy is considered a less invasive therapy approach to treat cancer, compared with conventional therapies. Therefore, invasive therapy was applied to investigate the effect of CQ on liver cancer. The results demonstrated that the two drug doses $(0.5$ and $1.5 \mathrm{mg} / \mathrm{kg})$ used inhibited tumor size (Fig. 3A and B) and weight (Fig. 3C), compared with results in control rats. Subsequently, to further investigate the effect of CQ on the expression of liver cancer markers, the expression levels of the liver cancer stem cell markers, including keratin 19 (K19) and sox9, were determined (24). RT-qPCR results revealed that CQ $(1.5 \mathrm{mg} / \mathrm{kg})$ downregulated the expression of K19 and sox9 (Fig. 3D and E). These findings were further verified using flow cytometric analysis (Fig. 3F-I).
To monitor the growth and survival of rats that had undergone interventional therapy, their body weight was recorded daily. Therefore, the body weight of rats treated with CQ-based interventional therapy was increased, compared with that of the control group (Fig. 4A). Concerning the survival rate of rats, 7/10, 3/10 and 1/10 rats died in the control group, 0.5 (low-dose) and $1.5 \mathrm{mg} / \mathrm{kg}$ (high-dose) CQ treatment groups, respectively (Fig. 4B). Notably, food and drinking water intake were increased in the CQ treatment groups, compared with the control group (Table II). Taken together, the aforementioned findings suggested that CQ-based interventional therapy may effectively treat liver cancer.

CQ induces apoptosis in HepG2 cells and 3D liver spheroids. To reveal the mechanism underlying the effect of CQ on suppressing liver cancer, the expression of the apoptosis-related genes, caspase-3 and caspase-9, in cells treated with CQ was determined. Therefore, treatment with 1,10 or $50 \mu \mathrm{M} C Q$ 


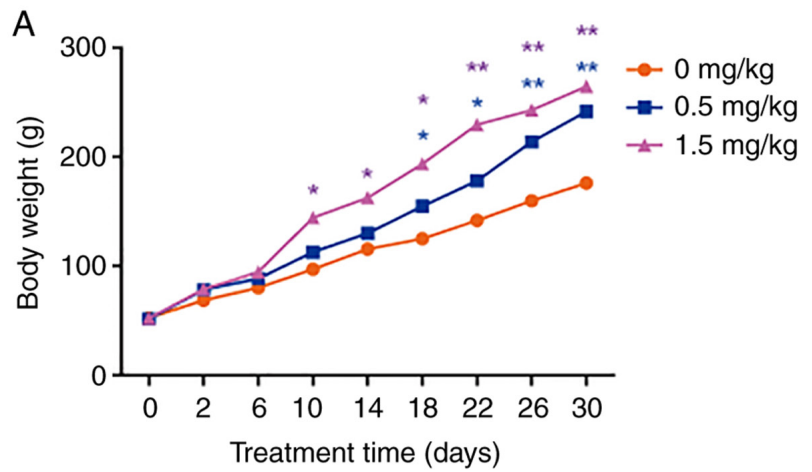

B Survival of data 1:survival proportions

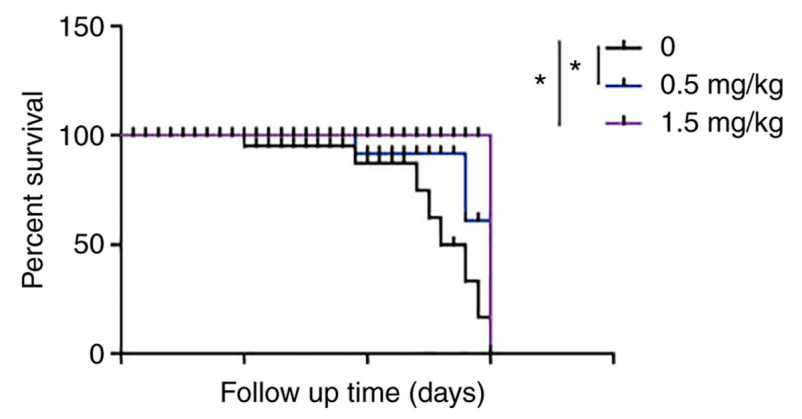

Figure 4. CQ increases body weight and survival rate of rats treated with different doses of CQ. (A) Body weight of rats treated with different doses of CQ $(n=10) .{ }^{*} \mathrm{P}<0.05$ and ${ }^{* *} \mathrm{P}<0.01$ vs. the control group. (B) The survival rate of rats treated with different doses of $\mathrm{CQ}(\mathrm{n}=10)$. ${ }^{*} \mathrm{P}<0.05$ vs. the control group. $\mathrm{CQ}$, chloroquine diphosphate.

notably increased the mRNA expression levels of caspase-3 and caspase-9 (Fig. 5A and B). Consistent with previous results, treatment of 3D liver spheroids with 1,10 or $50 \mu \mathrm{M} \mathrm{CQ}$ significantly upregulated the mRNA expression of caspase-3 and caspase-9 (Fig. 5C and $\mathrm{D} ; \mathrm{n}=4 ;{ }^{*} \mathrm{P}<0.05$ ). Taken together, these results suggested that the anticancer effects of CQ may be mediated by promoting liver cancer cell apoptosis.

\section{Discussion}

As liver cancer is considered one of the most serious types of cancer, great efforts have been made regarding the development of optimal treatment approaches. CQ has been used for a few decades as an antimalarial drug (25). It has been recently reported that CQ exerts antiviral effects against COVID-19 infection (25). The present study demonstrated that CQ may significantly inhibit the growth of HepG2 cells and 2D liver spheroids. Furthermore, CQ-based interventional therapy notably attenuated tumor growth, and increased the body weight and survival of Wistar rats. Notably, it was revealed that CQ markedly increased the expression of the apoptosis-related genes, caspase- 3 and caspase-9, indicating that the two molecules may underly the anticancer effects of CQ.

$\mathrm{CQ}$ is an old drug, which was developed in the last century (26). The drug is primarily used to treat infections caused by Plasmodium falciparum and is orally or parenterally administrated at a dose of $500 \mathrm{mg}$ or $10 \mathrm{mg} / \mathrm{kg}$, respectively (26). However, CQ has also been widely used to treat multiple diseases. CQ was found to render direct antiglobulin test-positive red blood cells (RBCs) free from membrane-bound $\mathrm{IgG}$ and
Table II. Daily feed and water intake for rats in different groups.

\begin{tabular}{lrrr}
\hline Treatment & $0 \mathrm{mg} / \mathrm{kg}$ & $0.5 \mathrm{mg} / \mathrm{kg}$ & $1.5 \mathrm{mg} / \mathrm{kg}$ \\
\hline Feed intake, g & $12.40 \pm 0.67$ & $14.90 \pm 0.64$ & $16.2 \pm 0.59$ \\
Drinking water, g & $5.60 \pm 0.75$ & $6.70 \pm 0.80$ & $9.90 \pm 0.85$ \\
\hline
\end{tabular}

Data are presented as the mean \pm standard error of the mean.

remove human leukocyte antigens (HLAs) from RBCs to aid in identifying or excluding the presence of antibodies against HLAs expressed on RBCs (27). In addition, treatment with $250 \mathrm{mg} /$ day CQ may prevent the exacerbation of systemic lupus erythematosus (28). Notably, accumulating evidence has indicated that CQ exerts antiviral effects against SARS-CoV-2 infection. A European group reported that CQ may inhibit the exacerbation of pneumonia, improve pulmonary imaging findings, promote a negative conversion of the virus and shorten the disease course in SARS-CoV-2-infected patients (13). It has also been reported that CQ exerts anticancer effects on several types of cancer. Wang et al (29) confirmed that CQ may enhance gefitinib-mediated apoptosis of cutaneous squamous cell carcinoma cells via inducing autophagy. Additionally, Wei et al (15) demonstrated that CQ was involved in the suppression of pancreatic cancer via regulating the expression profile of circular RNAs, long non-coding RNAs, microRNAs and mRNAs. Notably, Hu et al (30) confirmed that chloroquine triggered G0/G1 cell cycle arrest and promoted DNA damage and apoptosis in liver cancer cells in a dose- and time-dependent manner. The same study revealed that chloroquine attenuated tumor growth in an orthotopic xenograft model of liver cancer (30). The present study demonstrated that CQ may suppress the growth and viability of liver cancer cells in 2D and 3D models (Figs. 1 and 2). Furthermore, it was confirmed that the drug enhanced the expression of apoptosis-related genes, including caspase-3 and caspase-9 in the two models (Fig. 5). Furthermore, CQ has been found to exert anticancer effects against other types of cancer, including colon cancer (17), breast cancer (16) and lung cancer (31). The aforementioned reports and the present study suggested that CQ may serve as a broad anticancer drug.

To date, the goal remains the treatment of liver cancer patients using non-surgical minimally invasive therapies. Interventional therapy strategies have been increasingly applied in cancer due to their low invasiveness and relative safety (32). Different strategies, including transarterial chemoembolization, radiofrequency ablation, percutaneous ethanol injection, cryoablation, laser ablation and upcoming promising procedures such as focused ultrasound and gene therapy, have been applied as interventional therapy (33). In the present study, interventional therapy with hepatic artery catheterization was utilized, which allowed the transfer of CQ directly to the liver tumors, thereby providing increased treatment efficacy. It was revealed that CQ could remarkably decrease tumor size and weight (Fig. 3) and increase food intake, water consumption (Table II), body weight and survival rate (Fig. 4). Therefore, these results indicated that the combination of intervention therapy with CQ may display promising effects on liver cancer in rats. Additionally, this treatment approach could possibly confer a health benefit for liver cancer patients infected with plasmodium 
A

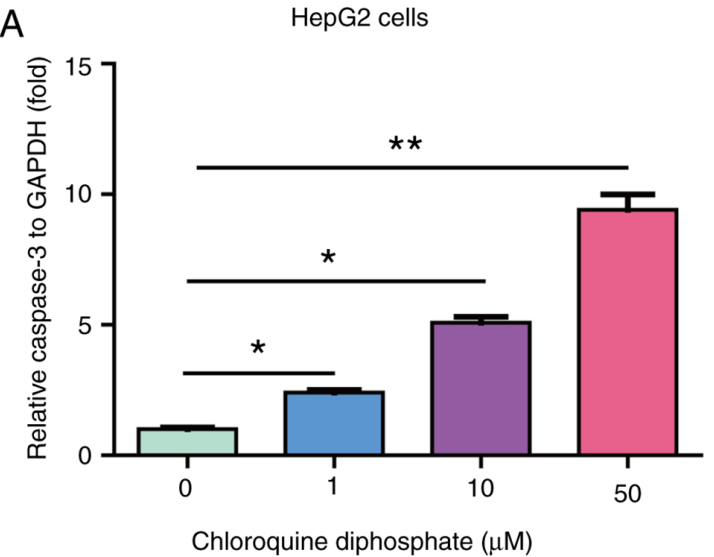

C

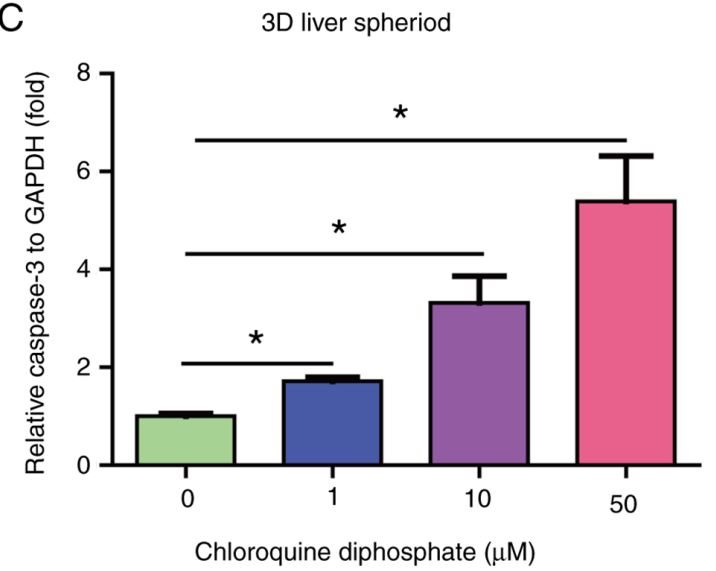

$\mathrm{B}$

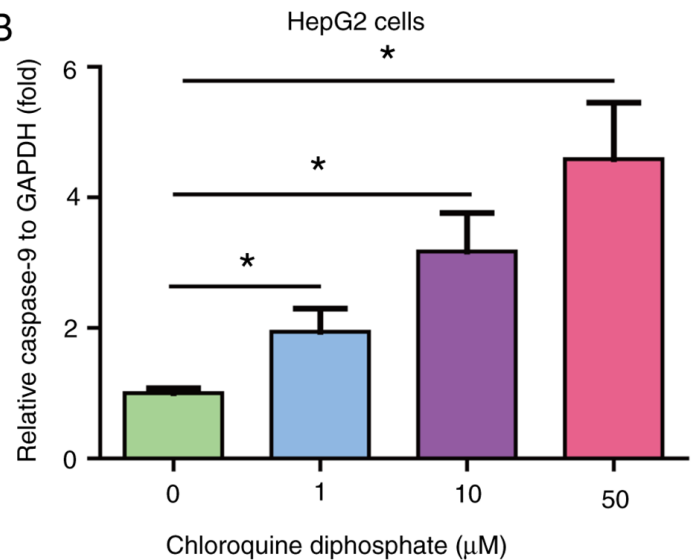

D

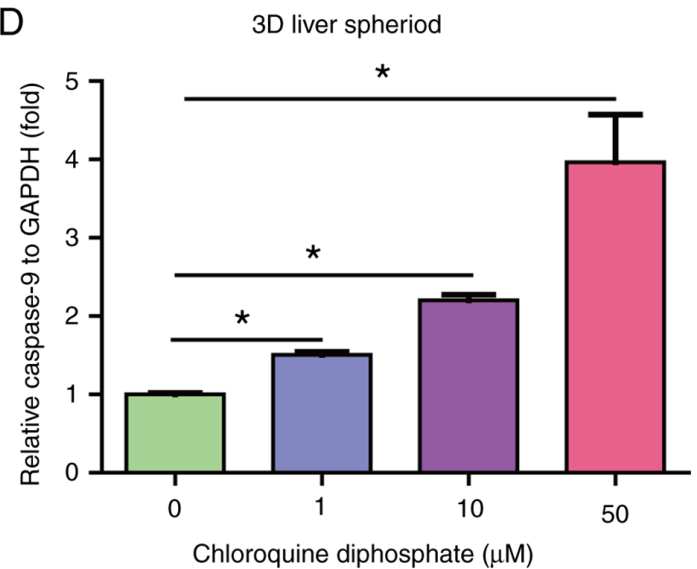

Figure 5. CQ induces apoptosis of HepG2 cells and 3D liver spheroids. Treatment of HepG2 cells with 1, 10 or $50 \mu \mathrm{M}$ CQ increased the mRNA expression levels of (A) caspase-3 and (B) caspase-9 ( $\mathrm{n}=4)$. ${ }^{*} \mathrm{P}<0.05$ and ${ }^{* * *} \mathrm{P}<0.01$ vs. the control group. (C) Treatment of 3D liver spheroids with 1,10 or $50 \mu \mathrm{M}$ CQ upregulated the mRNA expression levels of (C) caspase-3 and (D) caspase-9 ( $\mathrm{n}=4) .{ }^{*} \mathrm{P}<0.05$ vs. the control group. CQ, chloroquine diphosphate.

or SARS-CoV-2. Nevertheless, more efforts should be directed toward clarifying the effects of CQ on liver cancer in mammalian in vivo models and clinical practice.

Although the present study has demonstrated that CQ may suppress liver cancer via induction of apoptosis genes, there are several limitations to the present study. To begin with, it was confirmed that CQ increased expression of caspase-3 and caspase-9; however, apoptosis is a complicated physiological process, and multiple signaling pathways are involved in the process, including TNF signaling (34), the intrinsic mitochondrial pathway (35), the intrinsic endoplasmic reticulum pathway (35) and the microRNA pathway (36). As one of inhibitors of autophagy, CQ was reported to inhibit the growth of several tumors via mTOR-autophagy-induced apoptosis $(37,38)$, reactive oxygen species-dependent apoptosis (39) and the mitochondrial pathway (40). Therefore, it is plausible that the aforementioned apoptosis pathways require further investigation in order to identify the inhibitory effects of $\mathrm{CQ}$ on liver cancer. Another limitation to the present study is that only HepG2 cells were used as a model. A more advanced in vitro model, named organoid, has been developed by Prof. Dr. Hans Clevers of the Hubrecht Institute in Netherlands (41), and has been used in infectious diseases $(42,43)$, immunity (44), nutrition (45) and cancer $(46,47)$. Therefore, the liver cancer organoid may be a promising model for investigating the effects of CQ on liver cancer in future studies.
In conclusion, CQ demonstrated effective anticancer effects on HepG2 cells and 3D liver spheroids. The drug significantly inhibited cancer cell growth and viability in 2D and 3D in vitro models. Furthermore, the CQ-based intervention therapy effectively attenuated tumor size and weight, increased food intake and drinking water consumption, and improved body weight and survival rate. In addition, treatment of cells with CQ potently upregulated the expression of apoptosis-related genes. Therefore, the findings of the present study may provide novel insight into the development of safe and effective therapies for liver cancer.

\section{Acknowledgements}

Not applicable.

\section{Funding}

The study was supported by Hebei Provincial Health Department (grant no. 20160623).

\section{Availability of data and materials}

All data were generated at The Fourth Hospital of Hebei Medicine University and are available from the corresponding author on reasonable request. 


\section{Authors' contributions}

$\mathrm{XH}$ and WL had full access to all the data in the present study and take responsibility for the integrity of the data and the accuracy of the data analysis. WL conceived and designed the present study; XH and WL acquired, analyzed and interpreted the data; $\mathrm{XH}$ drafted the manuscript; WL critically revised the manuscript for important intellectual content; $\mathrm{XH}$ and WL performed the statistical analysis; XH and WL provided administrative, technical and material support; WL supervised the study. All authors read and approved the final manuscript.

\section{Ethics statement and consent to participate}

The present study was approved by the Animal Experimentation Committee of The Fourth Hospital of Medical University (Shijiazhuang, China).

\section{Patient consent for publication}

Not applicable.

\section{Competing interests}

The authors declare that they have no competing interests.

\section{References}

1. Yamashita $\mathrm{T}$ and Kaneko S: Liver cancer. Rinsho Byori 64 787-796, 2016 (In Japanese).

2. Li L and Wang H: Heterogeneity of liver cancer and personalized therapy. Cancer Lett 379: 191-197, 2016.

3. Anwanwan D, Singh SK, Singh S, Saikam V and Singh R: Challenges in liver cancer and possible treatment approaches. Biochim Biophys Acta Rev Cancer 1873: 188314, 2020.

4. Zheng R, Qu C, Zhang S, Zeng H, Sun K, Gu X, Xia C, Yang Z, Li H, Wei W, et al: Liver cancer incidence and mortality in China: Temporal trends and projections to 2030. Chin J Cancer Res 30: 571-579, 2018.

5. Shiraha H, Iwamuro $M$ and Okada $H$ : Hepatic stellate cells in liver tumor. Adv Exp Med Biol 1234: 43-56, 2020.

6. Losic B, Craig AJ, Villacorta-Martin C, Martins-Filho SN Akers N, Chen X, Ahsen ME, von Felden J, Labgaa I, D'Avola D, et al: Intratumoral heterogeneity and clonal evolution in liver cancer. Nat Commun 11: 291, 2020.

7. Guo Z, Chen W, Dai G and Huang Y: Cordycepin suppresses the migration and invasion of human liver cancer cells by downregulating the expression of CXCR4. Int J Mol Med 45: 141-150, 2020.

8. Liu CY, Chen KF and Chen PJ: Treatment of Liver Cancer. Cold Spring Harb Perspect Med 5: a021535, 2015.

9. Chan LK and Ng IO: Joining the dots for better liver cancer treatment. Nat Rev Gastroenterol Hepatol 17: 74-75, 2020.

10. Phillips WT, Bao A, Brenner AJ and Goins BA: Image-guided interventional therapy for cancer with radiotherapeutic nanoparticles. Adv Drug Deliv Rev 76: 39-59, 2014.

11. French JT, Goins B, Saenz M, Li S, Garcia-Rojas X, Phillips WT, Otto RA and Bao A: Interventional therapy of head and neck cancer with lipid nanoparticle-carried rhenium 186 radionuclide. J Vasc Interv Radiol 21: 1271-1279, 2010.

12. Weyerhäuser P, Kantelhardt SR and Kim EL: Re-purposing chloroquine for glioblastoma: Potential merits and confounding variables. Front Oncol 8: 335, 2018.

13. Borba MGS, Val FFA, Sampaio VS, Alexandre MAA, Melo GC, Brito M, Mourao MPG, Brito-Sousa JD, Baia-da-Silva D, Guerra MVF, et al: Effect of high vs low doses of chloroquine diphosphate as adjunctive therapy for patients hospitalized with severe acute respiratory syndrome coronavirus 2 (SARS-CoV-2) infection: A randomized clinical trial. JAMA Netw Open 3: e208857, 2020
14. Kashyap A, Kaur R, Baldi A, Jain UK, Chandra R and Madan J: Chloroquine diphosphate bearing dextran nanoparticles augmented drug delivery and overwhelmed drug resistance in Plasmodium falciparum parasites. Int J Biol Macromol 114: 161-168, 2018.

15. Wei DM, Jiang MT, Lin P, Yang H, Dang YW, Yu Q, Liao DY, Luo DZ and Chen G: Potential ceRNA networks involved in autophagy suppression of pancreatic cancer caused by chloroquine diphosphate: A study based on differentially-expressed circRNAs, IncRNAs, miRNAs and mRNAs. Int J Oncol 54: 600-626, 2019.

16. Jiang PD, Zhao YL, Deng XQ, Mao YQ, Shi W, Tang QQ, Li ZG, Zheng YZ, Yang SY and Wei YQ: Antitumor and antimetastatic activities of chloroquine diphosphate in a murine model of breast cancer. Biomed Pharmacother 64: 609-614, 2010.

17. Sasaki K, Tsuno NH, Sunami E, Kawai K, Hongo K, Hiyoshi M, Kaneko M, Murono K, Tada N, Nirei T, et al: Resistance of colon cancer to 5-fluorouracil may be overcome by combination with chloroquine, an in vivo study. Anticancer Drugs 23: 675-682, 2012.

18. Godoy P, Hewitt NJ, Albrecht U, Andersen ME, Ansari N, Bhattacharya S, Bode JG, Bolleyn J, Borner C, Bottger J, et al: Recent advances in $2 \mathrm{D}$ and $3 \mathrm{D}$ in vitro systems using primary hepatocytes, alternative hepatocyte sources and non-parenchymal liver cells and their use in investigating mechanisms of hepatotoxicity, cell signaling and ADME. Arch Toxicol 87: 1315-1530, 2013.

19. Miyamoto Y, Ikeuchi M, Noguchi H, Yagi T and Hayashi S: Spheroid formation and evaluation of hepatic cells in a three-dimensional culture device. Cell Med 8: 47-56, 2015.

20. Mazzei M, Vascellari M, Zanardello C, Melchiotti E, Vannini S, Forzan M, Marchetti V, Albanese F and Abramo F: Quantitative real time polymerase chain reaction (qRT-PCR) and RNAscope in situ hybridization (RNA-ISH) as effective tools to diagnose feline herpesvirus-1-associated dermatitis. Vet Dermatol 30: 491-e147, 2019.

21. Browning DJ: Pharmacology of chloroquine and hydroxychloroquine. In: Hydroxychloroquine and Chloroquine Retinopathy. Browning DJ (ed). Springer, New York, NY, pp35-63, 2014.

22. Faustino-Rocha A, Oliveira PA, Pinho-Oliveira J, Teixeira-Guedes C, Soares-Maia R, da Costa RG, Colaco B, Pires MJ, Colaco J, Ferreira R and Ginja M: Estimation of rat mammary tumor volume using caliper and ultrasonography measurements. Lab Anim (NY) 42: 217-224, 2013.

23. Yin YB, de Jonge HR, Wu X and Yin YL: Mini-gut: A promising model for drug development. Drug Discov Today 24: 1784-1794, 2019.

24. Kawai T, Yasuchika K, Ishii T, Miyauchi Y, Kojima H, Yamaoka R, Katayama H, Yoshitoshi EY, Ogiso S, Kita S, et al: SOX9 is a novel cancer stem cell marker surrogated by osteopontin in human hepatocellular carcinoma. Sci Rep 6: 30489, 2016.

25. Ferner RE and Aronson JK: Chloroquine and hydroxychloroquine in covid-19. BMJ 369: m1432, 2020.

26. Multicenter collaboration group of Department of Science and Technology of Guangdong Province and Health Commission of Guangdong Province for chloroquine in the treatment of novel coronavirus pneumonia: Expert consensus on chloroquine phosphate for the treatment of novel coronavirus pneumonia. Zhonghua Jie He He Hu Xi Za Zhi 43: 185-188, 2020 (In Chinese).

27. Aye T and Arndt PA: Utility of chloroquine diphosphate in the blood bank laboratory. Immunohematology 34: 98-102, 2018

28. Meinao IM, Sato EI, Andrade LE, Ferraz MB and Atra E: Controlled trial with chloroquine diphosphate in systemic lupus erythematosus. Lupus 5: 237-241, 1996.

29. Wang J, Wang C, Hu X, Yu C, Zhou L, Ding Z and Zhou M: Gefitinib-mediated apoptosis is enhanced via inhibition of autophagy by chloroquine diphosphate in cutaneous squamous cell carcinoma cells. Oncol Lett 18: 368-374, 2019.

30. Hu T, Li P, Luo Z, Chen X, Zhang J, Wang C, Chen P and Dong Z: Chloroquine inhibits hepatocellular carcinoma cell growth in vitro and in vivo. Oncol Rep 35: 43-49, 2016.

31. Fan C, Wang W, Zhao B, Zhang S and Miao J: Chloroquine inhibits cell growth and induces cell death in A549 lung cancer cells. Bioorg Med Chem 14: 3218-3222, 2006.

32. Brooks R and Bannigan K: Occupational therapy interventions in child and adolescent mental health: A mixed methods systematic review protocol. JBI Database System Rev Implement Rep 16: 1764-1771, 2018.

33. Guan YS and Liu Y: Interventional treatments for hepatocellular carcinoma. Hepatobiliary Pancreat Dis Int 5: 495-500, 2006. 
34. Perez-Garijo A, Fuchs Y and Steller H: Apoptotic cells can induce non-autonomous apoptosis through the TNF pathway. Elife 2: e01004, 2013.

35. Wong RS: Apoptosis in cancer: From pathogenesis to treatment. J Exp Clin Cancer Res 30: 87, 2011.

36. Pistritto G, Trisciuoglio D, Ceci C, Garufi A and D'Orazi G: Apoptosis as anticancer mechanism: Function and dysfunction of its modulators and targeted therapeutic strategies. Aging (Albany NY) 8: 603-619, 2016.

37. Liang Q, Xiao Y, Liu K, Zhong C, Zeng M and Xiao F. $\mathrm{Cr}(\mathrm{VI})$-induced autophagy protects L-02 hepatocytes from apoptosis through the ROS-AKT-mTOR pathway. Cell Physio Biochem 51: 1863-1878, 2018.

38. Yan L, Guo N, Cao Y, Zeng S, Wang J, Lv F, Wang Y and Cao X: miRNA-145 inhibits myocardial infarction-induced apoptosis through autophagy via Akt $3 / \mathrm{mTOR}$ signaling pathway in vitro and in vivo. Int J Mol Med 42: 1537-1547, 2018.

39. Tong Y, Zhang G, Li Y, Xu J, Yuan J, Zhang B, Hu T and Song G: Corilagin inhibits breast cancer growth via reactive oxygen species-dependent apoptosis and autophagy. J Cell Mol Med 22: 3795-3807, 2018 (Epub ahead of print).

40. Zeng Y, Li S, Wu J, Chen W, Sun H, Peng W, Yu X and Yang X Autophagy inhibitors promoted aristolochic acid I induced renal tubular epithelial cell apoptosis via mitochondrial pathway but alleviated nonapoptotic cell death in mouse acute aritolochic acid nephropathy model. Apoptosis 19: 1215-1224, 2014.

41. Hu H, Gehart H, Artegiani B, LÖpez-Iglesias C, Dekkers F, Basak O, van Es J, Chuva de Sousa Lopes SM, Begthel H, Korving $\mathrm{J}$, et al: Long-term expansion of functional mouse and human hepatocytes as 3D organoids. Cell 175: 1591-1606 e19, 2018.
42. Dutta D and Clevers H: Organoid culture systems to study host-pathogen interactions. Curr Opin Immunol 48: 15-22, 2017.

43. Yin Y, Chen S, Hakim MS, Wang W, Xu L, Dang W, Qu C, Verhaar AP, Su J, Fuhler GM, et al: 6-Thioguanine inhibits rotavirus replication through suppression of Racl GDP/GTP cycling. Antiviral Res 156: 92-101, 2018.

44. Angelini F, Corbetti F, Nassuato G, Okolicsanyi L and Zacchi C: Echography with portable equipment. Its possibilities and limits in the hepatobiliary area. Radiol Med 76: 337-339, 1988 (In Italian).

45. Yin YB, de Jonge HR, Wu X and Yin YL: Enteroids for nutritional studies. Mol Nutr Food Res 63: e1801143, 2019.

46. Nuciforo S,Fofana I,MatterMS,BlumerT,Calabrese D,Boldanova T, Piscuoglio S, Wieland S, Ringnalda F, Schwank G, et al: Organoid models of human liver cancers derived from tumor needle biopsies. Cell Rep 24: 1363-1376, 2018.

47. Sun L, Wang Y, Cen J, Ma X, Cui L, Qiu Z, Zhang Z, Li H, Yang RZ, Wang C, et al: Modelling liver cancer initiation with organoids derived from directly reprogrammed human hepatocytes. Nat Cell Biol 21: 1015-1026, 2019.

(i) $\Theta$ This work is licensed under a Creative Commons Attribution-NonCommercial-NoDerivatives 4.0 International (CC BY-NC-ND 4.0) License. 